\title{
Treadmill walking differently affects body composition and metabolic parameters of female rats from normal or small litters
}

\author{
GM Sakakima, ER dos Santos, GC Bueno, MS Rempel, JP Furlan, \\ CEM da Costa, VAF Godoi, MMD Pedrosa
}

Department of Physiological Sciences, State University of Maringá, Maringá, Brazil

Received: November 23, 2015

Accepted: May 16, 2016

\begin{abstract}
This work assessed whether walking affects bodily development and metabolic parameters of female rats raised in small litters (three pups, group S) or control litters (nine pups, group C). After weaning, some of the rats had five sessions per week of a 30-min treadmill walking (CE and SE), while the others remained sedentary (CS and SS) until the age of 120 days. Exercise caused a reduction of body weight $(\mathrm{CS} / \mathrm{CE}=1.18)$, Lee index $(\mathrm{CS} / \mathrm{CE}=1.04)$, fasting blood glucose $(\mathrm{CS} / \mathrm{CE}=1.35)$, mesenteric $(\mathrm{CS} / \mathrm{CE}=1.23)$, and ovarian fat $(\mathrm{CS} / \mathrm{CE}=1.33)$ in $\mathrm{CE}$, but only glucose was decreased in $\mathrm{SE}(\mathrm{SS} / \mathrm{SE}=1.16)$. The diameter of adipocytes decreased to a half in the small-litter groups. Exercise increased subcutaneous $(\mathrm{CS} / \mathrm{CE}=0.88$ and $\mathrm{SS} / \mathrm{SE}=0.71)$, but decreased retroperitoneal adipocytes $(\mathrm{CS} /$ $\mathrm{CE}=1.2$ and $\mathrm{SS} / \mathrm{SE}=1.3$ ). Litter size reduction had little impact on females at the age of 120 days, but the light physical activity seemed insufficient to counteract all the effects of lactational overfeeding. On the other hand, pups from exercised mothers had a decrease in their biometric and glycemic indexes, demonstrating the transgenerational action of regular, although light, exercise.
\end{abstract}

Keywords: obesity, exercise, small litter, blood glucose, adipocyte

\section{Introduction}

Obesity is a chronic disease, often associated with a positive energy balance, where genetic and environmental factors are involved, and it is linked to the appearance and aggravation of several metabolic disorders. The prevalence of obesity continues to increase in many countries; in Brazil, data from the World Health Organization show that the prevalence of overweight/obesity [body mass indexes (BMIs) above $25 \mathrm{~kg} \cdot \mathrm{m}^{-2}$ ] is higher than $50 \%$ in the population older than 15 years. This high prevalence is due to factors involving lifestyle, such as large caloric intakes and low levels of physical activity $(1,27)$. Life quality and expectancy are affected by excessive body fat. Insulin resistance, cardiovascular diseases, diabetes, and hypercholesterolemia are some examples of the susceptibility to metabolic and chronicdegenerative impairments that follow obesity $(7,20,36,42)$.

In recent years, excess body weight gain in childhood is calling increasing attention. The nutritional experiences at early life lead to the changes of growth and metabolism in later stages. The research demonstrates that the development of adipose cellularity at this early

Corresponding author: Julia Pedrosa Furlan

Department of Physical Education, State University of Maringá

Av. Colombo 5.790, Jardim Universitário, Maringá, Paraná 87020-900, Brazil

Phone: +55 443011 4698; Cellular phone: +55 449116 2280; E-mail: jpedrosafurlan@gmail.com 
stage can determine the body composition of the adult and thus the appearance and aggravation of obesity-related diseases $(6,14,23,35,37,38,42,45)$.

Physical inactivity is a significant adjuvant in the maintenance of obesity and its complications. Exercise, regardless of body weight loss, contributes to the preservation of the lean mass, appetite control, improvement of physical condition, increase of the resting metabolic rate, and has a positive interference on the individual's health $(20,24,33,39)$. Ciolac and Guimarães (8) state that an active life can prevent obesity, regardless of the kind of physical activity. To sustain this statement, they report that athletes, healthy individuals, nondiabetic obese, and diabetic subjects improve their insulin sensitivity when practicing exercise on a regular basis; the effects of exercise on this parameter are both acute and chronic $(8,24)$. Exercise beginning early in life has more persistent effects, and this probably occurs because exercise can alter the development of the central pathways regulating energy homeostasis (39). It is argued that, in humans, 30 min of moderate physical activity five times a week are adequate for body weight and fat control (32).

In rats, litter size reduction is a classical model of overweight/obesity and increased adiposity $(13,14,45)$. It is based on the modification of the post-natal nutritional environment (i.e., changing the number of pups per litter during lactation) as a mean of "programming" the central control of appetite and energy balance, resulting in the obese phenotype of the adult animal $(6,35,38,41,42)$. Common findings in small litters are greater body weight gain, increased levels of insulin and corticosterone, greater fat deposition, and hyperphagia $(25,41,42)$.

There is a great variety of possible levels of physical activity, but with laboratory animals, it is possible to design exercise protocols of specific intensities. In this study, it was assessed whether treadmill walking, a light and regular exercise, affects biometric and physiologic parameters of female rats raised in normal and small litters and whether exercising would affect the females' offspring.

\section{Materials and Methods}

\section{Animals}

The pregnant Wistar dams were obtained from the colony of the Central Animal House of the State University of Maringá, Paraná, Brazil, and kept at the animal house of the Department of Physiological Sciences under controlled light/dark cycles (12 h light/12 h dark) and temperature $\left(22 \pm 2{ }^{\circ} \mathrm{C}\right)$. Food and chow (Nuvilab CR1; Nuvital, Curitiba, PR, Brazil) were supplied ad libitum. The experimental protocols were approved by the Ethics Committee of the Institution (statement 015/2013).

The dams were housed in individual boxes, where they gave birth. The newborn litters were organized, so that each dam had three or nine pups, preferably females. Male pups were kept only when needed to complete the desired litter. The nine-pup litters were the control litter group (C) and the three-pup litters were the small-litter group (S). The assignment of the litters to group $\mathrm{C}$ or $\mathrm{S}$ depended on the litter size and number of females per litter, so that mixing of litters was kept to a minimum.

The pups remained with their mothers until the age of 21 days (weaning), when the female pups were put into a collective of plastic boxes in groups of three according to their original litter (C or S), with free access to water and chow. The male offspring was not included in this investigation. The $\mathrm{C}$ and $\mathrm{S}$ females were randomly subdivided into sedentary 
(S) and exercised (E), thus yielding four groups, CS, CE, SS, and SE. The exercise protocol of groups $\mathrm{CE}$ and $\mathrm{SE}$ is described in Physical activity section.

All the records and experimental procedures were carried out in the female rats. The animals were followed up for 120 days. The body weight and nasoanal length were recorded at the end of this period and were used to calculate the Lee index $\left(\left[{ }^{3} \sqrt{ }\right.\right.$ body weight $(\mathrm{g})$ body length $\left.\left.(\mathrm{cm})^{-1}\right] \cdot 1,000\right)$ of the experimental groups. The Lee index is used as an indicative of overweight/obesity in rats $(3,33)$. The BMI $\left(\mathrm{g} \cdot \mathrm{cm}^{-2}\right)$ for rats $(34)$ was also calculated.

The in vivo experiments of glucose tolerance test (GTT), insulin tolerance test (ITT), and exhaustion test were carried out between the age of 110 and 120 days. Overnight fasting preceded some protocols, as indicated in the following, and was of about $14 \mathrm{~h}$.

\section{Physical activity}

Soon after weaning, the female rats of the CE and SE groups were subjected to physical activity. This consisted of walking in a programmed treadmill (KT3000; Inbramed, Porto Alegre, RS, Brazil), adapted to the training of up to eight rats at the same time. Treadmill walking was carried out in five sessions per week, at different days and times, excluding the periods of 10 a.m.16 p.m. and 18 p.m. -6 a.m. There was a period of adaptation to the treadmill and to the activity. For the first 10 days (females aging 21-30 days), each session lasted 5 min with treadmill speed increasing from 0.2 to $0.6 \mathrm{~km} \cdot \mathrm{h}^{-1}$ for each two sessions. For the next 10 days, treadmill speed was kept at $0.6 \mathrm{~km} \cdot \mathrm{h}^{-1}$ and session duration progressively increased from 5 to $30 \mathrm{~min}$. After adaptation, each walking session lasted $30 \mathrm{~min}$ at the speed of $0.6 \mathrm{~km} \cdot \mathrm{h}^{-1}$ from the age of 40 to 120 days. The treadmill walking protocol of the $\mathrm{CE}$ and SE female rats did not change during pregnancy or lactation, except that it was interrupted during the third week of gestation and first week of lactation to prevent premature delivery and post-partum anxiety and cannibalism.

\section{Glucose tolerance test}

The female rats, after overnight fasting, were given oral glucose by gavage $\left(1.5 \mathrm{~g} \cdot \mathrm{kg}^{-1}\right.$ body weight). Blood samples were collected from a caudal incision at $0,15,30,45,60,90$, and $120 \mathrm{~min}, 0 \mathrm{~min}$ being immediately before glucose administration. Blood glucose was determined with test strips and glucose meter Optium-Exceed (Abbott, São Paulo, SP, Brazil) and expressed as $\mathrm{mg} \cdot \mathrm{dL}^{-1}$.

Based on the obtained data, the area under the curve (AUC) of the blood glucose variation during the 120 -min test was calculated. The index of blood glucose decay (kGTT, \% $\% \mathrm{~min}^{-1}$ ) from 30 to $120 \mathrm{~min}$ was also calculated.

\section{Insulin tolerance test}

After a 2-h fasting (from 8 a.m. to 10 a.m.), the rats were given an injection of regular insulin (1 U $\cdot \mathrm{kg}^{-1}$ body weight, i.p.; Novolin; Novo Nordisk, Montes Claros, MG, Brazil) for the experiments of insulin tolerance. Blood samples were collected from a caudal incision at $0,5,10,15,20,25,30,45,60,90$, and $120 \mathrm{~min}, 0 \mathrm{~min}$ being immediately before insulin injection. Blood glucose was determined with test strips and glucose meter and expressed as $\mathrm{mg} \cdot \mathrm{dL}^{-1}$. The index of blood glucose decay $\left(\mathrm{kITT}, \% \cdot \mathrm{min}^{-1}\right)$ was calculated for the first $30 \mathrm{~min}$ of the test (31).

\section{Exhaustion test}

After overnight fasting, the exhaustion test was performed as follows: the treadmill speed increased by $0.2 \mathrm{~km} \cdot \mathrm{h}^{-1}$ every $2 \mathrm{~min}$ from an initial speed of $0.4 \mathrm{~km} \cdot \mathrm{h}^{-1}$. Exhaustion was 
established as the moment the animal could not keep running. No painful stimuli were used to make the animals run.

\section{Biochemical assays}

The blood samples for the biochemical assays were collected after overnight fasting from a caudal incision. Appropriate test strips and Accutrend Plus (Roche, São Paulo, SP, Brazil) were employed. Lactate measurements were made immediately after the exhaustion test and are shown as $\mathrm{mmol} \cdot \mathrm{L}^{-1}$. For cholesterol and triglycerides, concentrations are given as $\mathrm{mg} \cdot \mathrm{dL}^{-1}$.

\section{Tissue removal}

The female rats were euthanized at the age of 120 days through excess anesthetic (sodium pentobarbital, $120 \mathrm{mg} \cdot \mathrm{kg}^{-1}$ body weight, i.p.), after overnight fasting. The visceral fats (retroperitoneal, ovarian, periuterine, and mesenteric), the subcutaneous fat, and the liver were removed and the weights were expressed as $100 \mathrm{~g}^{-1}$ body weight.

\section{Liver fat content}

The method of fat extraction with methanol and chloroform was employed (18). Samples of liver of about $1 \mathrm{~g}$ were dried at $40{ }^{\circ} \mathrm{C}$ until weight stabilization. To these dried samples, it was added $10 \mathrm{~mL}$ of chloroform:methanol solution $(2: 1, \mathrm{v} / \mathrm{v})$, homogenized and left to rest for $24 \mathrm{~h}$. Next, $8 \mathrm{~mL}$ of the resulting solution and $1.6 \mathrm{~mL}$ of saline were rested for $1 \mathrm{~h}$, centrifuged for $5 \mathrm{~min}$ at $1,000 \mathrm{r} / \mathrm{min}$ and the supernatant $(4 \mathrm{~mL})$ placed in a Petri dish for $24-48 \mathrm{~h}$ to evaporate. The lipid content was expressed as $\mathrm{mg} \cdot \mathrm{g}^{-1}$ of liver wet weight.

\section{Isolation and measurement of adipocytes}

Adipocytes were isolated from the subcutaneous, ovarian, and retroperitoneal fats following the methodology established by Rodbell with some adaptations (19, 40). After being removed, the fat pads were fragmented and placed in $4 \mathrm{~mL}$ digestion buffer (DMEM/HEPES $25 \mathrm{mM}$, bovine serum albumin fraction $\mathrm{V}$ - BSA in 4\% collagenase II $1.25 \mathrm{mg} \cdot \mathrm{mL}^{-1}, \mathrm{pH} 7.4,37^{\circ} \mathrm{C}$ ) for about $20 \mathrm{~min}$ under constant agitation $(150 \mathrm{r} / \mathrm{min})$ in an orbital water bath shaker. The digested tissue was filtered and washed three times with $25 \mathrm{~mL}$ glucose-free EARLE/HEPES/BSA (EHB) buffer $(20 \mathrm{mM}$ containing 1\%

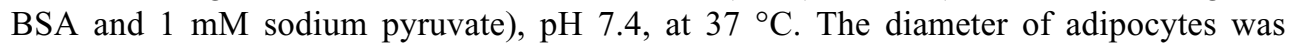
measured using an image analysis system (Image-Pro Plus 4.5; Media Cybernetics, Rockville, MD, USA). Fifty randomly chosen adipocytes per fat pad per animal of each group were measured.

\section{Evaluation of the litters}

Some 70-day-old female rats from each experimental group (CS, CE, SS, and SE) mated with non-treated males. Eight pups were left in each litter; after weaning, the male pups of these litters were kept in plastic boxes (four males per box), according to the original group of their dams. These animals were not subjected to physical activity and were given water and chow ad libitum until the age of 60 days. The naming of these groups of pups was made according to their dam's original group: CSp, CEp, and SEp. The mated SS females did not get pregnant, so there was no SSp group (see Assessment of the pups section and other sections of Results). 
The final (60 day) body weight and nasoanal length were recorded. After overnight fasting, blood glucose from a caudal incision was determined with test strips and glucose meter and expressed as $\mathrm{mg} \cdot \mathrm{dL}^{-1}$. The animals were euthanized by excess anesthetic (sodium pentobarbital, $120 \mathrm{mg} \cdot \mathrm{kg}^{-1}$ body weight, i.p.). The visceral fats (periepididymal, mesenteric, and retroperitoneal) and the liver were removed and their weights were expressed as $100 \mathrm{~g}^{-1}$ body weight.

\section{Statistical analysis}

Data are shown as mean \pm standard deviation (SD). Normality was checked through ShapiroWilk's test, followed by the appropriate $t$-test. Groups CS and SS were compared to test the effects of litter size. Groups CS and SS were compared with their respective exercised groups (CE and SE) to test the effects of physical activity. The data from the pups of groups CE and SE (named CEp and SEp, see Results section) were compared with those of group CS (CSp). Significant values were those below 0.05. Statistical analysis used GraphPad Prism v5 (GraphPad, San Diego, CA, USA).

\section{Results}

\section{Biometric data}

Table I shows the biometric data of the studied groups. At the age of 120 days, the Lee index was the only biometric parameter that was significantly higher in the SS female rats compared with those of the CS. Treadmill walking decreased body weight, Lee index, and BMI of group CE compared with CS, but did not change these parameters $(p>0.05)$ between groups SS and SE.

\section{Exhaustion test}

The sedentary groups ran significantly less time (CS 9.58 $\pm 2.89 \min , n=6$ and SS $10.39 \pm$ $1.89 \mathrm{~min}, n=9)$ and reached lower treadmill speeds than their corresponding exercised groups (CE $14.06 \pm 1.71 \mathrm{~min}, n=6$ and SE $13.87 \pm 1.75 \mathrm{~min}, n=6)(p<0.05)$. However, running time was not statistically different when sedentary (CS vs. SS) or exercised (CE vs. $\mathrm{SE})$ groups were compared $(p>0.05)$.

\section{Insulin tolerance test and glucose tolerance test}

Table II shows the data obtained during the GTT. Fasting blood glucose ( 0 min, immediately before glucose administration) was significantly lower in the exercised groups (CE and SE)

Table I. Biometric parameters at the age of 120 days of female rats raised in control (C) litters or small (S) litters, sedentary $(\mathrm{S})$, or exercised $(\mathrm{E})$

\begin{tabular}{|l|c|c|c|c|}
\hline & CS $(\boldsymbol{n}=\mathbf{6})$ & CE $(\boldsymbol{n}=\mathbf{6})$ & SS $(\boldsymbol{n}=\mathbf{1 0})$ & SE $(\boldsymbol{n}=\mathbf{6})$ \\
\hline Body weight $(\mathrm{g})$ & $295.60 \pm 13.22$ & $250.30 \pm 6.59^{*}$ & $287.60 \pm 18.33$ & $298.30 \pm 36.40$ \\
\hline Lee index & $287.00 \pm 8.93$ & $275.50 \pm 4.83^{*}$ & $299.80 \pm 8.15^{*}$ & $292.10 \pm 9.04$ \\
\hline BMI $\left(\mathrm{g} \cdot \mathrm{cm}^{-2}\right)$ & $0.57 \pm 0.04$ & $0.50 \pm 0.01 *$ & $0.61 \pm 0.04$ & $0.60 \pm 0.06$ \\
\hline
\end{tabular}

${ }^{*} p<0.05$ compared with group CS 
Table II. Glucose tolerance test (GTT) of female rats raised in control (C) litters or small (S) litters, sedentary (S), or exercised (E) at the age of 120 days after overnight fasting

\begin{tabular}{|c|c|c|c|c|}
\hline & $\operatorname{CS}(n=6-9)$ & CE $(n=5-8)$ & SS $(n=9)$ & SE $(n=6-9)$ \\
\hline $\begin{array}{l}\text { Blood glucose at } \\
0 \mathrm{~min}\left(\mathrm{mg} \cdot \mathrm{dL}^{-1}\right)\end{array}$ & $92.00 \pm 3.74$ & $68.40 \pm 2.79 * *$ & $100.8 \pm 9.35$ & $87.17 \pm 9.48 * * *$ \\
\hline $\begin{array}{l}\text { Blood glucose at } \\
15 \mathrm{~min}\left(\mathrm{mg} \cdot \mathrm{dL}^{-1}\right)^{*}\end{array}$ & $161.80 \pm 24.05^{*}$ & $124.30 \pm 13.69 *$ & $142.10 \pm 15.99 *$ & $150.30 \pm 22.63 *$ \\
\hline $\begin{array}{l}\text { Blood glucose at } \\
120 \mathrm{~min}\left(\mathrm{mg} \cdot \mathrm{dL}^{-1}\right)\end{array}$ & $90.66 \pm 19.59$ & $79.67 \pm 5.72 *$ & $96.10 \pm 13.21$ & $89.50 \pm 9.54$ \\
\hline AUC of GTT & $225.00 \pm 68.43$ & $191.20 \pm 78.04$ & $120.00 \pm 20.63^{* *}$ & $198.70 \pm 71.78 * * *$ \\
\hline $\operatorname{kGTT}\left(\% \cdot \min ^{-1}\right)$ & $0.49 \pm 0.16$ & $0.56 \pm 0.20$ & $0.47 \pm 0.18$ & $0.46 \pm 0.15$ \\
\hline
\end{tabular}

${ }^{*} p<0.05$ compared with 0 min of the group, ${ }^{* *} p<0.05$ compared with CS, ${ }^{* * *} p<0.05$ compared with SS

than in their sedentary pairs (CS and SS, respectively). Approximately 15 min after glucose administration, all the groups had blood glucose significantly higher than at $0 \mathrm{~min}$, but did not differ from one another $(p>0.05)$. At the end of the test $(120 \mathrm{~min})$, only group CE had significantly higher blood glucose than at $0 \mathrm{~min}$, while there was no difference between these two moments in the other groups $(p>0.05)$. Blood glucose did not differ $(p>0.05)$ at $120 \mathrm{~min}$ between groups $\mathrm{CS} / \mathrm{SS}, \mathrm{CS} / \mathrm{CE}$, and $\mathrm{SS} / \mathrm{SE}$.

The AUC of blood glucose variation during the GTT was significantly lower in group SS than in groups CS and SE. Groups CS and CE were not statistically different $(p>0.05)$.

The index of blood glucose decay (kGTT) was calculated for the interval from 30 to $120 \mathrm{~min}$, similar to what is often done with ITT (26). There was no difference $(p>0.05)$ between the groups for this index.

Table III shows the data from the ITT, after a 2-h fasting. In all the groups, blood glucose at $90 \mathrm{~min}$ (time of lower blood glucose) and at $120 \mathrm{~min}$ (final blood glucose) after insulin injection were significantly lower than at $0 \mathrm{~min}$. Blood glucose at $90 \mathrm{~min}$ was not different between the groups $(p>0.05)$. Group CS had higher blood glucose at $120 \mathrm{~min}$ when compared to groups SS and CE; groups SS and SE did not differ at $120 \mathrm{~min}(p>0.05)$. The index of blood glucose decay during the first $30 \mathrm{~min}$ of the test (kITT) was not different between the compared groups $(p>0.05)$.

\section{Biochemical assays}

Marked differences were found for fasting blood glucose (Table II) between groups $\mathrm{CS}$ and $\mathrm{CE}$, and SS and SE. Lower values were recorded in the exercised groups (CE and SE) compared with their respective sedentary pairs (CS and SS). After the 2-h fasting, before the ITT, the difference remained only between CS and CE (Table III). Cholesterol and triglycerides were not different between the compared groups (Table IV, $p>0.05$ ).

As for the blood lactate (Table IV), measured immediately after the exhaustion test, higher values were recorded in the CE and SS compared with CS. The groups SS and SE were similar $(p>0.05)$. There was no significant correlation in any of the groups $(p>0.05$, Pearson) between running time and blood lactate. 
Table III. Insulin tolerance test (ITT) of female rats raised in control (C) litters or small (S) litters, sedentary (S), or exercised (E) at the age of 120 days after $2 \mathrm{~h}$ of fasting

\begin{tabular}{|c|c|c|c|c|}
\hline & CS $(\boldsymbol{n}=\mathbf{6 - 9})$ & CE $(\boldsymbol{n}=\mathbf{5 - 8})$ & SS $(\boldsymbol{n}=\mathbf{9})$ & SE $(\boldsymbol{n}=\mathbf{6 - 9})$ \\
\hline $\begin{array}{c}\text { Blood glucose at } \\
0 \text { min }\left(\mathrm{mg} \cdot \mathrm{dL}^{-1}\right)\end{array}$ & $99.56 \pm 12.80$ & $62.67 \pm 9.34^{* *}$ & $98.30 \pm 13.30$ & $91.22 \pm 16.54$ \\
\hline $\begin{array}{c}\text { Blood glucose at } \\
90 \text { min }\left(\mathrm{mg} \cdot \mathrm{dL}^{-1}\right)\end{array}$ & $37.56 \pm 18.12^{*}$ & $31.25 \pm 11.73^{*}$ & $28.44 \pm 5.20^{*}$ & $27.33 \pm 4.09^{*}$ \\
\hline $\begin{array}{c}\text { Blood glucose at } \\
120 \mathrm{~min}\left(\mathrm{mg} \cdot \mathrm{dL}^{-1}\right)\end{array}$ & $57.22 \pm 6.14^{*}$ & $30.57 \pm 2.85^{* * * *}$ & $37.78 \pm 4.36^{* * * *}$ & $34.56 \pm 3.25^{*}$ \\
\hline kITT $\left(\% \cdot \mathrm{min}^{-1}\right)$ & $2.25 \pm 0.63$ & $2.51 \pm 1.20$ & $3.05 \pm 0.64$ & $3.00 \pm 0.95$ \\
\hline
\end{tabular}

$* p<0.05$ compared with 0 min of the group, $* * p<0.05$ compared with CS

Table IV. Biochemical assays of female rats raised in control (C) litters or small (S) litters, sedentary (S), or exercised (E) at the age of 120 days after overnight fasting

\begin{tabular}{|l|c|c|c|c|}
\hline & CS $(\boldsymbol{n}=\mathbf{6})$ & CE $(\boldsymbol{n}=\mathbf{4 - 6})$ & SS $(\boldsymbol{n}=\mathbf{1 0})$ & SE $(\boldsymbol{n}=\mathbf{5}-\mathbf{6})$ \\
\hline $\begin{array}{c}\text { Cholesterol } \\
\left(\mathrm{mg} \cdot \mathrm{dL}^{-1}\right)\end{array}$ & $158.20 \pm 7.44$ & $153.00 \pm 2.45$ & $160.60 \pm 6.06$ & $158.30 \pm 7.01$ \\
\hline $\begin{array}{c}\text { Triglycerides } \\
\left(\mathrm{mg} \cdot \mathrm{dL}^{-1}\right)\end{array}$ & $142.30 \pm 27.29$ & $170.60 \pm 44.00$ & $149.50 \pm 18.96$ & $133.50 \pm 31.33$ \\
\hline Lactate $\left(\mathrm{mmol} \cdot \mathrm{L}^{-1}\right)$ & $3.17 \pm 0.55$ & $4.38 \pm 0.82^{*}$ & $4.51 \pm 0.80 *$ & $3.96 \pm 0.38$ \\
\hline
\end{tabular}

$* p<0.05$ compared with CS

\section{Tissues and organs}

The relative weights of body fats and liver of the four experimental groups are shown in Table V. Group SS had a tendency of increase of all the fats in comparison with group CS, but this was significant only for the mesenteric and ovarian fats.

In both exercised groups, there was a tendency of decreased relative weight of almost all the fats, when compared with their sedentary counterparts. However, again only the mesenteric and ovarian fats of group CE were statistically different from those of CS. Groups SS and SE did not differ statistically $(p>0.05)$ in the relative weight of their fats.

The relative weight of the liver was not different between the groups (Table V, $p>$ $0.05)$. Liver fat content, in $\mathrm{mg} \cdot \mathrm{g}^{-1}$ of wet weight, was $0.08 \pm 0.02$ in CS $(n=8), 0.08 \pm 0.01$ in CE $(n=8), 0.08 \pm 0.01$ in SS $(n=7)$, and $0.08 \pm 0.02$ in SE $(n=7)$. These values were statistically similar $(p>0.05)$.

Table VI shows the diameter of the adipocytes isolated from the subcutaneous, ovarian, and retroperitoneal fats of the four experimental groups. Litter size reduction (group SS) decreased adipocyte diameter by about half in all these fats compared with the control (group CS). Treadmill walking affected adipocyte diameter differently on the fats assessed. However, even when statistical significance was not attained, the exercised groups had a tendency of larger subcutaneous and ovarian adipocytes and smaller retroperitoneal adipocytes than their sedentary counterparts. 
Table V. Relative weight of fats and liver of female rats raised in control (C) litters or small (S) litters, sedentary (S), or exercised $(\mathrm{E})$ at the age of 120 days

\begin{tabular}{|l|c|c|c|c|}
\hline $\begin{array}{l}\text { Relative weight } \\
\left(\mathbf{1 0 0}^{-\mathbf{1}} \mathbf{g} \text { body weight) }\right.\end{array}$ & $\mathbf{C S}(\boldsymbol{n}=\mathbf{6})$ & $\mathbf{C E}(\boldsymbol{n}=\mathbf{6})$ & $\mathbf{S S}(\boldsymbol{n}=\mathbf{1 0})$ & SE $(\boldsymbol{n}=\mathbf{5}-\mathbf{6})$ \\
\hline Retroperitoneal fat & $1.23 \pm 0.18$ & $1.17 \pm 0.28$ & $1.52 \pm 0.35$ & $1.44 \pm 0.42$ \\
\hline Mesenteric fat & $1.41 \pm 0.13$ & $1.15 \pm 0.41^{*}$ & $1.82 \pm 0.37^{*}$ & $1.54 \pm 0.29$ \\
\hline Periuterine fat & $1.52 \pm 0.23$ & $1.34 \pm 0.34$ & $1.75 \pm 0.39$ & $1.76 \pm 0.49$ \\
\hline Ovarian fat & $1.17 \pm 0.26$ & $0.88 \pm 0.28^{*}$ & $1.53 \pm 0.42^{*}$ & $1.18 \pm 0.44$ \\
\hline Total visceral fat & $5.28 \pm 0.50$ & $4.37 \pm 1.16$ & $6.43 \pm 1.18$ & $5.81 \pm 1.71$ \\
\hline Subcutaneous fat & $0.58 \pm 0.17$ & $0.89 \pm 0.31$ & $0.74 \pm 0.16$ & $0.59 \pm 0.26$ \\
\hline Liver & $2.85 \pm 0.35$ & $2.76 \pm 0.14$ & $2.55 \pm 0.21$ & $2.52 \pm 0.20$ \\
\hline
\end{tabular}

$* p<0.05$ compared with CS

Table VI. Diameter of adipocytes isolated from the ovarian, subcutaneous, and retroperitoneal fats of female rats raised in control (C) litters or small (S) litters, sedentary (S), or exercised (E) at the age of 120 days

\begin{tabular}{|l|c|c|c|c|}
\hline Diameter $(\mu \mathbf{m})$ & CS $(\boldsymbol{n}=\mathbf{4 - 5})$ & $\mathbf{C E}(\boldsymbol{n}=\mathbf{4 - 5})$ & SS $(\boldsymbol{n}=\mathbf{4}-\mathbf{5})$ & SE $(\boldsymbol{n}=\mathbf{4 - 5})$ \\
\hline Subcutaneous fat & $91.79 \pm 21.24$ & $103.95 \pm 8.55$ & $53.83 \pm 0.62^{*}$ & $76.19 \pm 12.32^{* *}$ \\
\hline Ovarian fat & $51.81 \pm 3.00$ & $117.93 \pm 5.46^{*}$ & $25.94 \pm 0.78^{*}$ & $34.52 \pm 5.72$ \\
\hline Retroperitoneal fat & $170.73 \pm 20.76$ & $142.97 \pm 4.26^{*}$ & $76.60 \pm 12.48^{*}$ & $59.24 \pm 3.51^{* *}$ \\
\hline
\end{tabular}

${ }^{*} p<0.05$ compared with $\mathrm{CS},{ }^{* *} p<0.05$ compared with SS

The calculation of cellularity for the retroperitoneal fat had a high correlation with the absolute weight of this fat ( $r=0.723 ; p<0.01$, Pearson). Higher cellularities were predicted for the small-litter groups than for the controls.

\section{Assessment of the pups}

The mated females from group SS did not have pups. As the number of female pups in group SE was small, only the male pups from groups CS, CE, and SE were evaluated, and were named CSp $(n=7)$, CEp $(n=12)$, and SEp $(n=14)$, respectively.

Table VII shows the biometric data of groups CSp, CEp, and SEp at the age of 60 days. The pups from exercised females, either from control or small litters (groups CEp and SEp) had body weight, nasoanal length, and weight/length ratio (WL) significantly lower than those of sedentary females (CSp). The BMI of these three groups, however, did not differ statistically $(p>0.05)$.

The relative weight of the visceral fat (sum of the epididymal, mesenteric, and retroperitoneal fats, $100 \mathrm{~g}^{-1}$ body weight) was $1.98 \pm 0.39$ in CSp, $1.53 \pm 0.25$ in CEp, and $1.77 \pm 0.37$ in SEp. The reduced visceral adiposity in the pups of the exercised dams reached statistical significance between CSp and CEp. 
Table VII. Biometric data of pups (p) of female rats raised in control (C) litters or small (S) litters, sedentary (S), or exercised (E), at the age of 60 days

\begin{tabular}{|l|c|c|c|}
\hline & CSp $(\boldsymbol{n}=7)$ & CEp $(\boldsymbol{n}=12)$ & SEp $(\boldsymbol{n}=14)$ \\
\hline Body weight $(\mathrm{g})$ & $319.00 \pm 32.06$ & $273.70 \pm 18.35^{*}$ & $282.60 \pm 16.5^{*}$ \\
\hline Nasoanal length $(\mathrm{cm})$ & $22.67 \pm 0.59$ & $21.50 \pm 0.44^{*}$ & $21.74 \pm 0.54^{*}$ \\
\hline WL ratio $\left(\mathrm{g} \cdot \mathrm{cm}^{-1}\right)$ & $14.06 \pm 1.22$ & $12.73 \pm 0.77^{*}$ & $13.00 \pm 0.60^{*}$ \\
\hline BMI $\left(\mathrm{g} \cdot \mathrm{cm}^{-2}\right)$ & $0.62 \pm 0.05$ & $0.59 \pm 0.04$ & $0.60 \pm 0.03$ \\
\hline
\end{tabular}

${ }^{*} p<0.05$ compared with CSp

The relative weight of the liver $\left(100 \mathrm{~g}^{-1}\right.$ body weight) was not significantly different $(p>0.05)$ between CSp (4.50 \pm 1.07$)$, CEp (3.50 \pm 0.36$)$, and SEp $(3.68 \pm 0.51)$.

The overnight fasting blood glucose of the pups was $78.57 \pm 8.30 \mathrm{mg} \cdot \mathrm{dL}^{-1}$ in $\mathrm{CSp}$, $69.25 \pm 5.94 \mathrm{mg} \cdot \mathrm{dL}^{-1}$ in CEp, and $65.77 \pm 9.98 \mathrm{mg} \cdot \mathrm{dL}^{-1}$ in SEp. The blood glucose of the pups from exercised dams (CEp and SEp) was statistically lower than that of CSp.

\section{Discussion}

Several authors state that early post-natal overnutrition, such as that caused by reducing the litter size during lactation, is a causative agent of later obesity (i.e., in adulthood) and is linked to metabolic and cardiovascular diseases $(12,36,42,45)$. Disturbances in the hypothalamic circuitry controlling feeding behavior and body weight management during this critical period of development are involved $(11,13,23,38,45,50)$.

Surprisingly, the sedentary female rats from the small litters (group SS) did not show body weight significantly different from that of the controls (group CS) at the age of 120 days. Although an increased body weight is frequently found in rats from small litters $(11,12$, $14,25,41,42,50)$, it is not a universal observation. Stefanidis and Spencer (46) and Velkoska et al. (48) note that the effects of the small litter on body weight and adiposity are more marked in young animals and tend to smooth out with age. In addition, gender differences are also observed (46). Both of these factors - i.e., female rats aging 120 days - may have prevented the overt obesity in the small litter that would be expected at adult age. In addition, weight control in the rat might be restored when they are fed with normal, instead of highly caloric, diet (46).

On the other hand, the female SS rats had greater Lee index than those of group CS, as well as greater relative weight of some visceral fats, indicating that the small litter size during lactation did promote an alteration on body composition of the adult SS females. Even more significant and consistent was adipocyte size: those of the SS had half the diameter of those of the CS, and calculated cellularity was much greater. Taken as a whole, these biometric and morphometric data indicate that the small litter had a long-term impact on the female SS rats $(14,17)$.

Regular physical activity since childhood helps in the control of body weight and adiposity, and a sedentary lifestyle, together with increased food ingestion, is a major cause of the epidemics of obesity $(1,27,32)$. According to Matsudo and Matsudo (32), exercise in obese subjects alters the body composition even without changes in body weight or BMI. The 
comparison of the control groups of this study (CS and CE) showed that group CE had: (1) decreased body weight, Lee index, and BMI at the age of 120 days, (2) decreased body fat (significant for the mesenteric and ovarian fats); and (3) increased ovarian and decreased retroperitoneal adipocyte size. On the other hand, the female SE rats did not have significant changes of these values when compared to the sedentary (SS), except for increased subcutaneous and retroperitoneal adipocyte size, despite having a better performance during the exercise sessions than group CE, as observed by Santos et al. (43). In this way, treadmill walking had some positive effects on group CE, while group SE was, for the major part, refractory to this intervention. In this context, it seems relevant to the observation that the adrenergic efferentation is reduced in overfed rats subjected to exercise (44), which could explain, at least partially, the absence of body weight and fat weight loss in the female SE rats. Nery et al. (33) report the opposite changes of body weight in rats from small and large litters subjected to swimming, compared with their sedentary counterparts, and argue that swimming was not efficient in promoting the changes of body composition.

There was a trend (or significant) decrease of fat pad weight in the exercised groups (CE and SE) compared with their sedentary counterparts (CS and SS), but this was not always matched by adipocyte size, which tended to behave in the opposite direction (larger adipocytes in the exercised vs. the sedentary groups). It has to be noted, however, that there was a consistent and significant decrease of the retroperitoneal adipocyte diameter in the exercised groups (CE and SE). As visceral fat is associated with the changes in peripheral and hepatic insulin sensitivity seen in obesity $(5,15,29,49)$, the reduced size of retroperitoneal adipocytes promoted by treadmill walking may be relevant.

In addition, although cellularity of the retroperitoneal fat was an estimation, the higher values for the small-litter females are in accordance with the literature data, that adipose tissue cellularity is established by nutritional conditions early in life (9); this feature was not reversed by exercise in the present investigation.

Obesity in human populations and several rodent models is associated with insulin resistance and glucose intolerance $(7,29,42)$. In these instances, it is expected as follows: 1) higher fasting blood glucose, 2) greater blood glucose increase and lower rate of decay after oral administration of glucose, and 3) lower decrease of blood glucose after insulin administration. During the GTT, orally given glucose is absorbed by the gastrointestinal tract to the blood, increasing blood glucose, and stimulating the release of insulin by pancreatic beta cells (28). Next, insulin, especially on liver, adipose tissue and muscle, promote glucose uptake, oxidation, and storage, thus decreasing blood glucose. The kinetics of the change on blood glucose after its oral administration is an indirect indicative of the efficacy of endogenous insulin in restoring the blood glucose levels.

Groups CS and SS did not differ on their glycemic kinetics during the $120 \mathrm{~min}$ of the GTT, as can be seen by their similar blood glucose values at 0,15 , and 120 min and kGTT. However, the AUC was significantly lower in the SS. Probably, this was because, although the differences between CS and SS were not significant, in group SS blood glucose at 0 and 120 min was higher, and at 15 min lower, than in CS. Taken together, these small differences resulted in a mean AUC statistically smaller in group SS. Larger AUCs in rats from small litters are a more common finding (42), but not always (20). In this study, the GTT values are consistent with the biometric data discussed above, and do not indicate overt changes in glucose tolerance in the female SS rats.

Fasting blood glucose ( 0 min of GTT) was lower in the exercised than in the sedentary groups, and that could be the result of an increased basal sensitivity to endogenous insulin 
caused by treadmill walking during 100 days in groups CE and SE. The return of the AUC of GTT of group SE to values similar to the control groups (CS and CE) resulted from the lower basal ( $0 \mathrm{~min})$ and higher peak (15 min) blood glucose during the test compared with the SS; this combination increased the blood glucose variation (i.e., the AUC) during the $120 \mathrm{~min}$ of the test.

ITT follows the behavior of blood glucose after the administration of a "bolus" of insulin $(30,31)$. The kinetics of the blood glucose reflects the capacity of the exogenous insulin in promoting glucose uptake by the tissues. The return of blood glucose toward the initial values is an indicative of the: (1) action of the endogenous counterregulatory hormones - glucagon, catecholamines, growth hormone, and glucocorticoids - than counteract insulin to prevent blood glucose from falling below physiologically acceptable values and (2) vanishing of the exogenous insulin (10).

The SS female rats did not differ from those of CS during the ITT except for the lower blood glucose at $120 \mathrm{~min}$. Therefore, insulin resistance, common in rodents from small litters, was not found in the females of this study. Despite the lower basal blood glucose in the exercised groups, there was no evidence of increased insulin sensitivity, as assessed by ITT.

Running times before exhaustion did not differ between groups CS and SS; however, blood lactate was higher in the SS. Although there is much debate about the physiological significance of lactate assays in exercise and sports physiology $(2,4,16,22)$, higher lactate levels with equal running times/speeds before exhaustion in incremental tests may indicate more marked anaerobic metabolism, and thus poorer aerobic conditioning, which would be plausible in this study considering the characteristics of group SS compared to group CS.

The exercised rats (CE and SE) had a better performance during the test of exhaustion than their sedentary counterparts (CS and SS), demonstrating that regular long-term physical activity improved aerobic conditioning, reflected in the greater time to exhaustion. Once again, there was no correlation between blood lactate and time to exhaustion in the incremental test. The post-test lactate levels were higher in CE than in CS, but did not differ significantly between SS and SE. Taken together with the greater time to exhaustion in group CE compared with $\mathrm{CS}$, and considering that the final speed reached by $\mathrm{CE}$ at the end of the test was $60 \%$ higher than in group CS, it is possible to suggest that group CE could have a better anaerobic capacity and overall performance. It is worth stressing, once more, that lactate measurements and their metabolic meaning are still the focus of intense research in exercise physiology; a few studies employ treadmill incremental tests and these analyses do not have a standard methodology.

The inability of the female SS rats of giving birth was a surprising observation. A report on the reproductive function of these animals is presented by Santos et al. (43).

The male rats whose mothers were exercised (groups CEp and SEp) had biometric and adiposity measurements - body weight, nasoanal length, WL ratio, liver weight, and visceral fat - and fasting blood glucose lower than those from sedentary mothers (group CSp). The results described in this study seem to point to a beneficial effect of regular physical activity of the dams on their litters, which is independent of maternal adiposity, as both groups of litters from exercised mothers had lower biometric and blood glucose indexes than those of sedentary mothers. Experimental interventions on the mothers are often reflected on their litters, but the specific transgenerational outcome depends on the intervention (e.g., physical activity protocol, food manipulation, etc.) and the parameter under assessment (7, 21, 26, 37, $38,47)$. It should be noted that treadmill walking in the pregnant dams from CE and SE was 
interrupted only during the third week of gestation and first week of lactation, so that exercise was present during critical periods of the pre- and post-natal development of the offspring $(7,45)$.

\section{Conclusions}

The model of obesity in rats by litter size reduction had little impact on the females of this study, in light of the results obtained compared to those frequently found in the literature. Factors such as age (120 days rather than younger animals) and gender (female rats instead of males) may have influenced the results. It deserves to mention, though, that adipocytes were consistently smaller in the small-litter groups than in the control groups, regardless of exercise.

Treadmill walking had some different effects on the exercised control and small-litter groups, suggesting that the effects of overfeeding during lactation, even when subtle, might change the response to light physical activity later in life. It is possible that early overfeeding, even when adult obesity is not seen, demands higher levels of physical activity to positively change the body composition. Nevertheless, the response of the retroperitoneal (i.e., visceral) adipocytes was a positive observation in both exercised groups.

\section{Acknowledgement}

The authors would like to thank L. K. R. Babata, V. S. Romão, and M. Fabrício for their technical assistance.

\section{REFERENCES}

1. Abete I, Navas-Carretero S, Marti A, Martinez JA: Nutrigenetics, nutrigenomics of caloric restriction. Prog. Mol. Biol. Transl. Sci. 108, 323-346 (2012)

2. Bassett DR, Howley ET: Limiting factors for maximum oxygen uptake, determinants of endurance performance. Med. Sci. Sports Exerc. 32, 70-84 (2000)

3. Bernardis LL, Patterson BD: Correlation between "Lee index", carcass fat content in weanling, adult female rats with hypothalamic lesions. J. Endocrinol. 40, 527-528 (1968)

4. Billat LV: Use of blood lactate measurements for prediction of exercise performance, for control of training. Recommendations for long-distance running. Sports Med. 22, 157-175 (1996)

5. Booth A, Magnuson A, Foster M: Detrimental, protective fat: body fat distribution, its relation to metabolic disease. Horm. Mol. Biol. Clin. Investig. 17, 13-27 (2014)

6. Castellano JM, Bentsen AH, Sánchez-Garrido MA, Ruiz-Pino F, Romero M, Garcia-Galiano D, Aguilar E, Pinilla L, Diéguez C, Mikkelsen JD, Tena-Sempere M: Early metabolic programming of puberty onset: impact of changes in postnatal feeding, rearing conditions on the timing of puberty, development of the hypothalamic kisspeptin system. Endocrinology 152, 3396-3408 (2011)

7. Chen H, Simar D, Lambert K, Mercier J, Morris MJ: Maternal, postnatal overnutrition differentially impact appetite regulators, fuel metabolism. Endocrinology 149, 5348-5356 (2008)

8. Ciolac EG, Guimarães GV: Exercício físico e síndrome metabólica [Physical exercise and metabolic syndrome]. Rev. Bras. Med. Esporte 10, 319-330 (2004)

9. Cryer A, Jones HM: The early development of white adipose tissue. Effects of litter size on the lipoprotein lipase activity of four adipose-tissue depots, serum immunoreactive insulin, tissue cellularity during the first four weeks of life in the rat. Biochem. J. 178, 711-724 (1979)

10. Cryer PE: Glucose counterregulation: prevention, correction of hypoglycemia in humans. Am. J. Physiol. 264, 149-155 (1993)

11. Davidowa H, Li Y, Plagemann A: Altered neuronal responses to feeding-relevant peptides as sign of developmental plasticity in the hypothalamic regulatory system of body weight. Zh. Vyssh. Nerv. Deiat. Im. I P Pavlova 53, 663-670 (2003) 
12. Davidowa H, Plagemann A: Different responses of ventromedial hypothalamic neurons to leptin in normal, early postnatally overfed rats. Neurosci. Lett. 293, 21-24 (2000)

13. Davidowa H, Plagemann A: Insulin resistance of hypothalamic arcuate neurons in neonatally overfed rats. Neuroreport 18, 521-524 (2007)

14. Duff DA, Snell K: Effect of altered neonatal nutrition on the development of enzymes of lipid, carbohydrate metabolism in the rat. J. Nutr. 112, 1057-1066 (1982)

15. Einstein FH, Atzmon G, Yang XM, Ma XH, Rincon M, Rudin E, Muzumdar R, Barzilai N: Differential responses of visceral, subcutaneous fat depots to nutrients. Diabetes 54, 672-678 (2005)

16. Faude O, Kindermann W, Meyer T: Lactate threshold concepts: how valid are they? Sports Med. 39, 469-490 (2009)

17. Faust IM, Johnson PR, Hirsch J: Long-term effects of early nutritional experience on the development of obesity in the rat. J. Nutr. 110, 2027-2034 (1980)

18. Folch J, Lees M, Sloane Stanley GH: A simple method for the isolation, purification of total lipides from animal tissues. J. Biol. Chem. 226, 497-509 (1957)

19. Foletto MP, Ferrari F, Peres SB, de Moraes SMF, Segatelli TM, Mareze-da-Costa CE: Effects of anabolic steroid treatment associated with physical training in adipose tissue of male Wistar rats. Acta Sci. Health Sci. 37, 19-24 (2015)

20. Gomes RM, Marques AS, Torrezan R, Scomparin DX, Mathias PCF, Rinaldi W: Efeito de um programa de exercício físico moderado em ratos de diferentes modelos de obesidade [Effect of moderate exercise program on rats from different models of obesity]. Rev. da Educ. Física/UEM 23, 285-294 (2012)

21. Gorski J: Exercise during pregnancy: maternal, fetal responses. A brief review. Med. Sci. Sports Exerc. 17, 407-416 (1985)

22. Green S, Dawson B: Measurement of anaerobic capacities in humans. Definitions, limitations, unsolved problems. Sports Med. 15, 312-327 (1993)

23. Grove KL, Grayson BE, Glavas MM, Xiao XQ, Smith MS: Development of metabolic systems. Physiol. Behav. 86, 646-660 (2005)

24. Henriksen EJ: Invited review: effects of acute exercise, exercise training on insulin resistance. J. Appl. Physiol. 93, 788-796 (2002)

25. Hou M, Liu Y, Zhu L, Sun B, Guo M, Burén J, Li X: Neonatal overfeeding induced by small litter rearing causes altered glucocorticoid metabolism in rats. PLoS One 6, 1-9 (2011)

26. Kendig MD, Ekayanti W, Stewart H, Boakes RA, Rooney K: Metabolic effects of access to sucrose drink in female rats, transmission of some effects to their offspring. PLoS One 10, e0131107 (2015)

27. King B, Jiang Y, Su X, Xu J, Xie L, Standard J, Wang W: Weight control, endocrine hormones, cancer prevention. Exp. Biol. Med. 238, 502-508 (2013)

28. Komatsu M, Takei M, Ishii H, Sato Y: Glucose-stimulated insulin secretion: a newer perspective. J. Diabetes Investig. 4, 511-516 (2013)

29. Kuba VM, Cavalieri PM, Christóforo AC, Junior RF, Caetano R, Coeli CM, Athayde A: Resistência insulínina e perfil metabólico em pacientes com síndrome dos ovários policísticos de peso normal e sobrepeso/obesidade [Insulin resistance and metabolic profile in lean and overweight/obese polycystic ovary syndrome patients]. Arq. Bras. Endocrinol. Metabol. 50, 1026-1033 (2006)

30. Lee MY, Koh JH, Nam SM, Jung PM, Sung JK, Kim SY, Shin JY, Shin YG, Chung CH: Short insulin tolerance test can determine the effects of thiazolidinediones treatment in type 2 diabetes. Yonsei Med. J. 49, 901-908 (2008)

31. Lehnen AM, Leguisamo NM, Pinto GH, Markoski MM, De Angelis K, Machado UF, Schaan B: The beneficial effects of exercise in rodents are preserved after detraining: a phenomenon unrelated to GLUT4 expression. Cardiovasc. Diabetol. 9, 67 (2010)

32. Matsudo VKR, Matsudo SMM: Atividade física no tratamento da obesidade [Physical exercise in treating obesity]. Einstein 4, 29-43 (2006)

33. Nery CS, Pinheiro IL, Muniz GS, de Vasconcelos DAA, de França SP, do Nascimento E: Medidas Murinométricas e Eficiência Alimentar em Ratos Provenientes de Ninhadas Reduzidas na Lactação e Submetidos ou Não ao Exercício de Natação [Murinometric evaluations and feed efficiency in rats from reduced litter during lactation and submitted or not to swimming exercise]. Rev. Bras. Med. Esporte 17, 49-55 (2011)

34. Novelli ELB, Diniz YS, Galhardi CM, Ebaid GMX, Rodrigues HG, Mani F, Fernandes AAH, Cicogna AC, Novelli Filho JLVB: Anthropometrical parameters, markers of obesity in rats. Lab. Anim. 41, 111-119 (2007) 
35. Orozco-Solís R, Matos RJB, Guzmán-Quevedo O, Lopes de Souza S, Bihouée A, Houlgatte R, Manhães de Castro R, Bolaños-Jiménez F: Nutritional programming in the rat is linked to long-lasting changes in nutrient sensing, energy homeostasis in the hypothalamus. PLoS One 5, e13537 (2010)

36. Patel MS, Srinivasan M: Metabolic programming due to alterations in nutrition in the immediate postnatal period. J. Nutr. 140, 658-661 (2010)

37. Patel MS, Srinivasan M: Metabolic programming in the immediate postnatal life. Ann. Nutr. Metab. 58, 18-28 (2011)

38. Patel MS, Srinivasan M, Laychock SG: Metabolic programming: role of nutrition in the immediate postnatal life. J. Inherit. Metab. Dis. 32, 218-228 (2009)

39. Patterson CM, Levin BE: Role of exercise in the central regulation of energy homeostasis, in the prevention of obesity. Neuroendocrinology 87, 65-70 (2008)

40. Rodbell M: Metabolism of isolated fat cells. Effect of hormones on glucose metabolism, lipolysis. J. Biol. Chem. 239, 375-380 (1964)

41. Rodrigues AL, de Moura EG, Passos MCF, Dutra SCP, Lisboa PC: Postnatal early overnutrition changes the leptin signalling pathway in the hypothalamic-pituitary-thyroid axis of young, adult rats. J. Physiol. 587, 2647-2661 (2009)

42. Rodrigues AL, De Souza EPG, Da Silva SV, Rodrigues DSB, Nascimento AB, Barja-Fidalgo C, De Freitas MS: Low expression of insulin signaling molecules impairs glucose uptake in adipocytes after early overnutrition. J. Endocrinol. 195, 485-494 (2007)

43. Santos ER, Sakakima GM, Pedrosa MMD: Walking restores the reproductive function of female rats from reduced litters, a classical model of obesity. Rev. Saúde e Pesqui 7, 455-463 (2014)

44. Scheurink AJ, Balkan B, Strubbe JH, van Dijk G, Steffens AB: Overfeeding, autonomic regulation, metabolic consequences. Cardiovasc. Drugs Ther. 10, 263-273 (1996)

45. Spencer SJ: Early life programming of obesity: the impact of the perinatal environment on the development of obesity, metabolic dysfunction in the offspring. Curr. Diabetes Rev. 8, 55-68 (2012)

46. Stefanidis A, Spencer SJ: Effects of neonatal overfeeding on juvenile, adult feeding, energy expenditure in the rat. PLoS One 7, e52130 (2012)

47. Vanheest JL, Rodgers CD: Effect of exercise in diabetic rats before, during gestation on maternal, neonatal outcomes. Am. J. Physiol. Endocrinol. Metab. 36, 727-733 (1997)

48. Velkoska E, Cole TJ, Morris MJ: Early dietary intervention: long-term effects on blood pressure, brain neuropeptide Y, adiposity markers. Am. J. Physiol. Endocrinol. Metab. 288, E1236-E1243 (2005)

49. Vilmann LS, Thisted E, Baker JL, Holm J-C: Development of obesity, polycystic ovary syndrome in adolescents. Horm. Res. Paediatr. 78, 269-278 (2012)

50. Zippel U, Plagemann A, Davidowa H: Altered action of dopamine, cholecystokinin on lateral hypothalamic neurons in rats raised under different feeding conditions. Behav. Brain Res. 147, 89-94 (2003) 